\title{
Value Investing: International Comparison
}

Anna Beukes, Northern Alberta Institute of Technology, Canada

\begin{abstract}
Based on accumulated empirical evidence, the academic community has generally come to agree that value investment strategies, on average, outperform growth investment strategies (Chan and Lakonishok, 2004:71). An influential article by Fama and French (1992) tested the notion that United States stock prices might be related to the ratio of a firm's book value of common equity $(B V)$ to its market value of common equity (MV). It found that companies with high book value relative to market value of equity (BV/MV) outperform the market. This finding led to extensive testing for the value premium in developed countries around the world. Fama and French (1998a) tested it with data from twelve major European countries, as well as from Australia and the Far East. They found that between 1975 and 1995 in almost every country, value stocks delivered a higher return than growth stocks. The value premium has not been tested with the same vigor in third world or developing countries, which raises the question whether the value premium is only a first world phenomena and, if not, how third world value premiums compare to those found in developed countries. This paper compares the size of the value premium in the USA, UK, and some continental European countries with South African data.
\end{abstract}

Keywords: value premium; value versus growth investment strategy; value premium international comparison; investment strategies; value premium South Africa; investment returns

\section{INTRODUCTION}

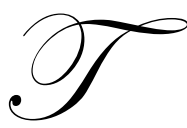

he recent academic interest in value versus growth investment strategies was sparked by an influential article by Fama and French (1992). Fama and French were by no means the first to suggest that it might be profitable to buy shares trading at low prices relative to fundamentals such as earnings, assets, dividends, etc. This concept dates back to the 1930s when Graham and Dodd (1934), who became known as the fathers of value investing, first suggested that taking company fundamentals into consideration when buying shares is a prerequisite for good returns. Fama and French were also not the only ones, or even the first, to test the notion that a relationship exists between a company's BV/MV and its share price. Rosenberg, Reid and Lanstein (1985) and Chopra, Lakonishok and Ritter (1992) tested this hypothesis before them in the USA and found strong and positive correlations. Chan, Hamao, and Lakonishok (1991) found similar results for Japan. However, Fama and French's work became instrumental in the development of style-specific benchmarks. Their BV/MV ratio became an important indicator of a portfolio's orientation toward either growth or value: value portfolios are companies with high BV/MV values, whereas growth portfolios comprise of companies with low BV/MV values.

Since 1992, the notion that the shares of value companies outperform the market was extensively tested around the world. Fama and French (1998a) tested it themselves with data from twelve major European countries as well as from Australia and the Far East. They found that between 1975 and 1995 in almost every country, value stocks delivered a higher return than growth stocks. Even after refining their study by incorporating other value measurements, such as earnings/price, cash flow/price, and dividend/price, they found similar value premiums. This value premium phenomenon was also tested in some emerging markets, such as Indonesia, Singapore and Taiwan, by Naughton and Veeraraghavan (2005) ${ }^{1}$ and South Africa by Beukes (2010), but not with the same vigor as it had been studied in the developed world.

\footnotetext{
${ }^{1}$ The empirical method used by Naughton and Veeraraghavan to study the value premium in Indonesia, Singapore and Taiwan was completely different from the method used by the studies included in this paper for comparative purposes and could therefore not be included.
} 
An important question is whether the value premium should be considered a first world phenomenon or not. Various authors, such as Schatzberg and Reiber (1992) and Antoniou et al. (1997), argued that a value investment strategy might be more profitable in less developed markets that are characterized by thinner trading and dominated by small, less sophisticated investors who do not instantaneously respond to new information. These factors should lead to what Rouwenhorst (1999) called a "Third World" premium, which reflects the greater exposure to risk with which smaller markets have to contend.

The purpose of this paper is to test for the presence of the value premium in a developing country (South Africa) and to compare the size of the value premium between some major developed countries (USA, UK and Europe) and South Africa.

\section{Why South African Data?}

South Africa is an interesting case study because it has a well-established, sizable and fairly liquid financial market that is internationally recognized as well-managed and effective in allocating capital. It is also isolated and has so far not been studied intensively, which means that its data have not been over-analyzed and it does not suffer from the well known data limitations of over-mining or data snooping (Lo and MacKinlay, 1990). All these factors make South Africa a good case study to compare with developed economies. The existence of the value premium in South Africa has been investigated by various researchers using a variety of methods, most notably Plaistowe and Knight (1986), Page and Palmer (1991), Maritz and Klerck (1997), Gates (1997), Robins, Sandler and Durand (1999), Fraser and Page (2000), Van Rensburg and Robertson (2003a), Auret and Sinclaire (2006), Bailey and Gilbert (2007), and Beukes (2010).

\section{METHOD}

Various empirical methods have been employed to test for the value premium in various locations internationally. The method used by all studies included in this paper was the one popularized by Lakonishok, Shleifer, and Vishny in 1994 (henceforth denoted as LSV) - the USA results from that work are also utilized for comparative purposes in this paper. Other studies also used for comparative purposes are from the UK by Gregory, Harris and Michou (2001), and from Europe by Brouwer, Van der Put and Veld (1997). The latter contains data from France, Germany, the Netherlands and the UK.

The LSV method consists of classifying and sorting companies into portfolios based on a value measure. Companies trading on the various exchanges, such as the London Stock Exchange in the case of the UK (Gregory, Harris and Michou, 2001), and the Johannesburg Stock Exchange in the case of South Africa (Beukes 2010), were grouped into portfolios, from high value to high growth portfolios, based on one-dimensional value classifications (BV/MV, cash flow-to-price ratio, earnings-to-price ratio and past sales growth), as well as two-dimensional classifications (sales growth and book-value or sales growth and cash flow). For each portfolio, returns were recorded for up to five years after portfolio formation. The test asserts that the value premium was present if the value portfolio, on average, outperformed the growth portfolio in the years following portfolio formation. The reason for including two-dimensional tests is to see if a value portfolio is more profitable if based jointly on past performance (proxied by sales growth) and expected future performance (proxied by BV/MV or CF/P or E/P).

\section{Descriptions of Comparative Studies}

The study of Lakonishok, Shleifer, and Vishny (1994) covered USA stocks trading on the NYSE and AMEX between 1963 and 1990. They used COMPUSTAT data for accounting variables and stock price data from CRSP. Ten portfolios were formed annually based on accounting ratios, such as book-value-to-market-value (BV/MV), cash-flow-to-price (CF/P), earnings-to-price (E/P) and sales growth (PSG) for the one-dimensional test. Under the two-dimensional test, firms were independently classified into three subgroups according to each of two fundamental variables, such as PSG and CF/P or PSG and BV/MV.

An annual "buy and hold" strategy was employed and equally weighted portfolios were used. Returns were calculated annually for years 1 through 5 after portfolio formation. Results are for year-on-year share price returns and are calculated as follows: 
- $\quad$ First year (year1) after portfolio formation: (Share price in year ${ }_{1}$ - share price at portfolio formation)/Share price at portfolio formation

- Second year $\left(\right.$ year $_{2}$ ) after portfolio formation: (Share price in year $_{2}-$ share price in year ${ }_{1}$ )/share price in year $_{1}$

Returns for the third, fourth, and fifth year after portfolio formation were calculated on the same basis. In addition to yearly returns, the average return over the five post-formation years was also reported and those are the values used for comparison purposes.

Gregory, Harris, and Michou (2001) studied UK stocks trading on the London Stock Exchange between 1975 and 1998. They used annual accounting data from Datastream and monthly share price return data from the London Share Price Database. Ten portfolios were formed annually based on the same accounting ratios used by LSV for one-dimensional portfolio formation; namely, book-value-to-market-value (BV/MV), cash-flow-to-price $(\mathrm{CF} / \mathrm{P})$, earnings-to-price (E/P), and sales growth (PSG). For the two-dimensional tests, portfolios were not sorted independently on PSG and CF/P or PSG and BV/MV, like LSV did, but portfolios were first formed on the basis of PSG and then within each sales growth portfolio, stocks were further sorted by BV/MV, E/P or CF/P.

Similar to the LSV study, returns were calculated and reported for every year from 1 through 5 after portfolio formation as well as an average return over the five post-formation years. Value-weighted portfolios were used which means each stock's contribution to the portfolio return was weighted in proportion to its market capitalization at portfolio formation date. This way of doing portfolio formation may have had a marked influence on the results obtained.

Brouwer, Van der Put, and Veld (1997) studied European stock markets with data for all large continental European stock exchanges, including Paris (France), Frankfurt (Germany), Amsterdam (The Netherlands), as well as London (UK). The UK provided the largest percentage of companies (42\%) included in the study and the Netherlands the lowest percentage $(13 \%)$. For one-dimensional tests, they used three accounting ratios; namely, book-value-to-market-value (BV/MV), cash-flow-to-price (CF/P), earnings-to-price (E/P), all of which were defined in the same way as LSV. They formed five portfolios annually and calculated and reported results similar to LSV for every year from 1 through 5 after portfolio formation as well on average over the five post-formation years. Like LSV, they also used equally-weighted portfolios. Their study, however, did not include two-dimensional tests.

The study done by the present author (Beukes, 2010) focused on South Africa with data made available by McGregor BFA from Johannesburg, South Africa. All companies trading on the Johannesburg Stock Exchange (JSE) between 1972 and 2001 were classified and listed, based on one-dimensional value classifications, such as book-value-to-market-value (BV/MV), cash flow-to-price ratio (CF/P), earnings-to-price ratio (E/P), and past sales growth (PSG), all defined in the same way as LSV. After classification, all companies were grouped into five portfolios (quintiles) ${ }^{2}$. In line with all of the other studies, portfolios were adjusted annually, resulting in twentynine years of portfolio formation between 1972 and 2001.

For the South African two-dimensional tests, portfolios were created in the same way as in the Gregory, Harris, and Michou (2001) study. Stocks were sorted into three portfolios based on past performance and proxied by PSG. The bottom 30\% of companies with the lowest PSG formed one portfolio, the middle $40 \%$ of companies formed the second portfolio, and the top 30\% of companies with the highest PSG formed the third portfolio. Within each of these three PSG portfolios, stocks were further sorted into three more portfolios based on expected future performance and proxied by BV/MV, resulting in nine portfolios. As with the one-way classification, for each of the nine two-way portfolios, annual returns were computed in each of the subsequent five-year periods following portfolio formation. The same procedure was used to carry out the second two-dimensional test based on a two-way classification of PSG and CF/P.

\footnotetext{
${ }^{2}$ Using USA data, Lakonishok, Shleifer and Vishny (1994) used ten (i.e. decile) portfolios. So did Gregory, Harris and Michou (2001) with data from the London Stock Exchange. Brouwer, Van der Put and Veld (1997) used five portfolios (quintiles) for their European study. The South African study also used five portfolios because the number of companies trading on the JSE did not merit ten portfolios.
} 


\section{Comparisons Based On One-Dimensional Tests}

Tables 1 and 2 present and compare international findings for one-dimensional tests. Table 1 shows the difference between the average annual returns generated in the five years after portfolio formation by the top value portfolio and the top growth portfolio. This difference is called the "spread" and is equivalent to the size of the value premium.

Table 13: One-Dimensional Results - Value versus Growth Spread (Averaged Over Five Years)

\begin{tabular}{|l|c|c|c|c|}
\hline \multicolumn{1}{|c|}{ Value Measure } & USA & UK & Europe & South Africa \\
\hline BV/MV & 10.5 & 8.95 & 10.00 & 11.84 \\
\hline CF/P & 11.00 & 3.92 & 20.8 & 19.35 \\
\hline E/P & 7.6 & 3.98 & 5.01 & 11.95 \\
\hline PSG & 6.8 & 2.16 & n/a & 0.68 \\
\hline
\end{tabular}

Analyzing the results in Table $1^{4}$ shows that the BV/MV portfolio formation basis in South Africa produced average returns that are close to the averages recorded in the USA and Europe. In the UK, BV/MV was the most profitable way of carrying out portfolio formation (compared to CF/P, E/P and PSG in that country), but it is the only market where the difference between value and growth portfolios based on BV/MV was less than 10\%.

In the USA, Europe and South Africa, CF/P was the most profitable way of doing portfolio formation. This is not completely surprising as the valuation of an asset is the present value of future cash flows. What is surprising is that $\mathrm{CF} / \mathrm{P}$ portfolios were substantially less profitable in the UK. Also, CF/P, as basis for portfolio in the UK, produced a spread of less than $4 \%$, while $\mathrm{CP} / \mathrm{P}$ portfolios in the other countries all produced double digit spreads $19 \%$ in South African, $20.8 \%$ in European and $11 \%$ in the USA.

With E/P as the basis for portfolio formation, South African data produced a higher average annual return spread than that observed in any other region under review. The South African E/P was the only one which produced a double digit spread. It is noteworthy that the high value of $11.95 \%$ is the spread when using E/P that excludes extraordinary items ${ }^{5}$. This is consistent with the method by which E/P was calculated in all the studies under review. It was also possible to calculate an E/P spread that includes extraordinary items for South Africa (given the availability of data) and if these values are used for comparison purposes, the spread shrinks to $4 \%$, which is almost identical to the UK value.

With PSG as the basis for portfolio formation, South African results produced a spread which is completely dissimilar to the other three ways of portfolio formation. PSG produced a return difference of less than $1 \%$ between the value and growth portfolios, while all other value measures (BV/MV, CF/P, and E/P) produced double digit figures. However, when extending the one-dimensional comparison in Table 2 by looking not only at the spread, but also at the actual returns generated by the top value and top growth portfolios, the top value portfolio based on PSG in South Africa generated a higher return (22\%) than any of the top PSG value portfolios in other regions. So, although the PSG way of doing portfolio formation in South Africa is not particularly impressive in terms of spread,

\footnotetext{
3 All values in this table are percentages $(\%)$ and refer to average annual return over five post-formation years. "Spread" refers to the difference between the performance of the top value portfolio and top growth portfolio, which is portfolio 1 and portfolio 5 in the case of Europe and South African and portfolios 1 and 10 in the case of the USA and UK.

${ }^{4}$ There are unavoidable complications in table 1, because the European portfolio includes the UK, which is also represented in a separate column. This is deemed justifiable as it reflects London's status as an important single market in its own right. It is also worth noting that there are more international studies available than those included here for comparative purposes. For example, similar stock market data is available for the Netherlands and New Zealand. The reason why these findings are not included is because they only used a three year annually adjusted return time frame, while the international studies presented here all used a five year period.
}

5 Extraordinary items refer to items of a non-recurring nature. 
the top value portfolio generates a higher share price return than its international counterparts. In fact, all South Africa's top value portfolios, whether based on $\mathrm{PSG}, \mathrm{BV} / \mathrm{MV}, \mathrm{CF} / \mathrm{P}$, or $\mathrm{E} / \mathrm{P}$, generated a higher return than their international counterparts.

Table 26 : One-Dimensional Test - Performance Of Top Value And Growth Portfolios And Spread

\begin{tabular}{|l|c|c|c|c|c|c|c|c|c|}
\hline $\begin{array}{l}\text { Portfolio } \\
\text { based on }\end{array}$ & \multicolumn{3}{|c|}{ USA } & \multicolumn{3}{c|}{ UK } & \multicolumn{3}{c|}{ South Africa } \\
\hline & $\begin{array}{c}\text { Top Value } \\
\text { Portfolio }\end{array}$ & $\begin{array}{c}\text { Top } \\
\text { Growth } \\
\text { Portfolio }\end{array}$ & Spread & $\begin{array}{c}\text { Top } \\
\text { Value } \\
\text { Portfolio }\end{array}$ & $\begin{array}{c}\text { Top } \\
\text { Growth } \\
\text { Portfolio }\end{array}$ & Spread & $\begin{array}{c}\text { Top } \\
\text { Value } \\
\text { Portfolio }\end{array}$ & $\begin{array}{c}\text { Top } \\
\text { Growth } \\
\text { Portfolio }\end{array}$ & Spread \\
\hline BV/MV & 19.8 & 9.3 & 10.5 & 27.42 & 18.47 & 8.95 & 30.07 & 18.23 & 11.84 \\
\hline CF/P & 20.1 & 9.1 & 11.00 & 24.49 & 20.57 & 3.92 & 29.69 & 10.34 & 19.35 \\
\hline E/P & 19.0 & 11.4 & 7.6 & 24.62 & 20.64 & 3.98 & 27.34 & 23.46 & 3.88 \\
\hline PSG & 19.5 & 12.7 & 6.8 & 21.05 & 18.89 & 2.16 & 22.28 & 21.60 & 0.68 \\
\hline
\end{tabular}

\section{Comparisons Based On Two-Dimensional Tests}

Comparing international markets becomes more revealing when the two-dimensional basis for portfolio formation is brought under the spotlight, as Table 3 shows. In addition to comparing the results from the three countries, Table 3 makes it possible to ascertain whether it is more profitable to base portfolio formation on two- as opposed to one-dimensional criteria. For the former to be the case, the spread between the value and growth portfolio in the two-dimensional case must exceed the spread in the one-dimensional case. Alternatively, returns generated by the top value portfolio under two-dimensional portfolio formation must be higher than returns generated by the same portfolio under one-dimensional tests.

As shown in Figure 1, it is clear that sorting portfolios in the USA, UK, and South Africa on the basis of PSG-BV/MV (the first of the two-dimensional tests) does produce a larger spread than when portfolios are based on PSG alone, but the spread is not larger than when portfolios are based on BV/MV alone; at least not in South Africa and the USA. In the UK, the spread difference of $11.81 \%$ on PSG-BV/MV portfolios is not only larger for portfolios based on PSG, but also larger than the $8.95 \%$ spread for portfolios based on BV/MV alone.

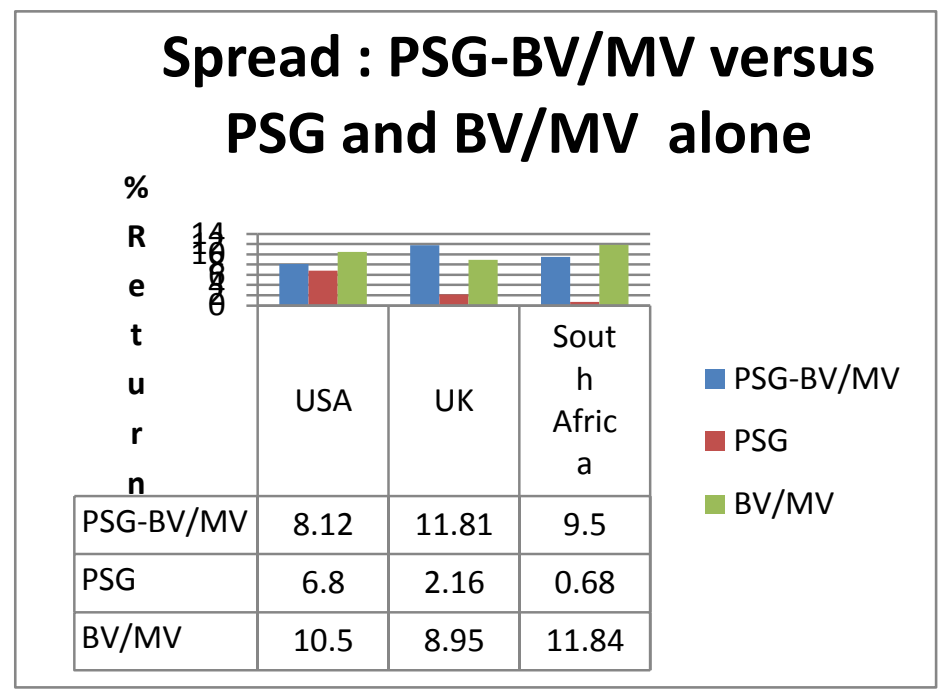

Figure 1

\footnotetext{
6 All values in this table are percentages (\%), and refer to the average annual return over five post-formation years. "Spread" again refers to the difference between the performance of the top value portfolio and the bottom growth portfolio. Brouwer et al. (1997) unfortunately did not include two-dimensional ways of portfolio formation in their European study; therefore, their results could not be included in the two-dimensional table for comparative purposes.
} 
Table 3: One And Two-Dimensional Test Comparisons

\begin{tabular}{|c|c|c|c|c|c|c|c|c|c|}
\hline \multirow{2}{*}{$\begin{array}{l}\text { Portfolio } \\
\text { Based On }\end{array}$} & \multicolumn{3}{|c|}{ USA } & \multicolumn{3}{|c|}{ UK } & \multicolumn{3}{|c|}{ South Africa } \\
\hline & $\begin{array}{c}\text { Top Value } \\
\text { Portfolio }\end{array}$ & $\begin{array}{c}\text { Top } \\
\text { Growth } \\
\text { Portfolio }\end{array}$ & Spread & $\begin{array}{c}\text { Top } \\
\text { Value } \\
\text { Portfolio }\end{array}$ & $\begin{array}{l}\text { Bottom } \\
\text { Growth } \\
\text { Portfolio }\end{array}$ & Spread & $\begin{array}{c}\text { Top } \\
\text { Value } \\
\text { Portfolio }\end{array}$ & $\begin{array}{c}\text { Top } \\
\text { Growth } \\
\text { Portfolio }\end{array}$ & Spread \\
\hline $\mathrm{BV} / \mathrm{MV}$ & 19.8 & 9.3 & 10.5 & 27.42 & 18.47 & 8.95 & 30.07 & 18.23 & 11.84 \\
\hline $\mathrm{CF} / \mathrm{P}$ & 20.1 & 9.1 & 11.00 & 24.49 & 20.57 & 3.92 & 29.69 & 10.34 & 19.35 \\
\hline $\mathrm{E} / \mathrm{P}$ & 19.0 & 11.4 & 7.6 & 24.62 & 20.64 & 3.98 & 27.34 & 23.46 & 3.88 \\
\hline PSG & 19.5 & 12.7 & 6.8 & 21.05 & 18.89 & 2.16 & 22.28 & 21.60 & 0.68 \\
\hline $\begin{array}{l}\text { PSG- } \\
\text { BV/MV }\end{array}$ & 21.12 & 13.0 & 8.12 & 25.00 & 13.19 & 11.81 & 18.9 & 9.4 & 9.5 \\
\hline $\begin{array}{l}\text { PSG- } \\
\text { CF/P }\end{array}$ & 22.1 & 11.4 & 10.70 & 24.14 & 13.31 & 10.83 & 22.2 & 2.7 & 19.5 \\
\hline
\end{tabular}

Comparing the returns generated by the top value portfolios reveals that the yield generated by the top value portfolio under the PSG-BV/MV (the first two-dimensional portfolio formation) in the USA is $21.1 \%$, which is more than when portfolios are based on BV/MV alone (19.8\%) or on PSG alone (19.5\%) (the one-dimensional ways). The yield generated by the top value portfolio under PSG-BV/MV in the UK is also more (25\%) than the yield generated by the top value portfolio based on PSG alone $(21.05 \%)$, but not more than the yield of the top $\mathrm{BV} / \mathrm{MV}$ portfolio (27.42\%). Both large developed countries' results in this regard contrast with the South African results, where the yield of the top PSG-BV/MV portfolio is less (18.9\%) than either of the top portfolios when the one-dimensional BV/MV (30.07\%) or PSG (22.28\%) bases are used.

As shown in Figure 2, when the second of the two-dimensional tests (PSG-CF/P) is analyzed, it again shows a larger spread in returns in all three countries than when portfolios are based on one-dimensional PSG alone. However, this does not occur when portfolio formation is based on CF/P alone, as can be seen in the USA where the two-dimensional test does produce a value premium of $10.70 \%$ compared to the $11 \%$ value premium on the onedimensional CF/P test. The South African figures show almost identical values for the two approaches: the spread on PSG-CF/P is $19.50 \%$ and on the one-dimensional CF/P the spread is $19.35 \%$. In the UK, however, the $10.83 \%$ spread on the two-dimensional test is substantially more than the $3.92 \%$ on the one-dimensional CF/P test.

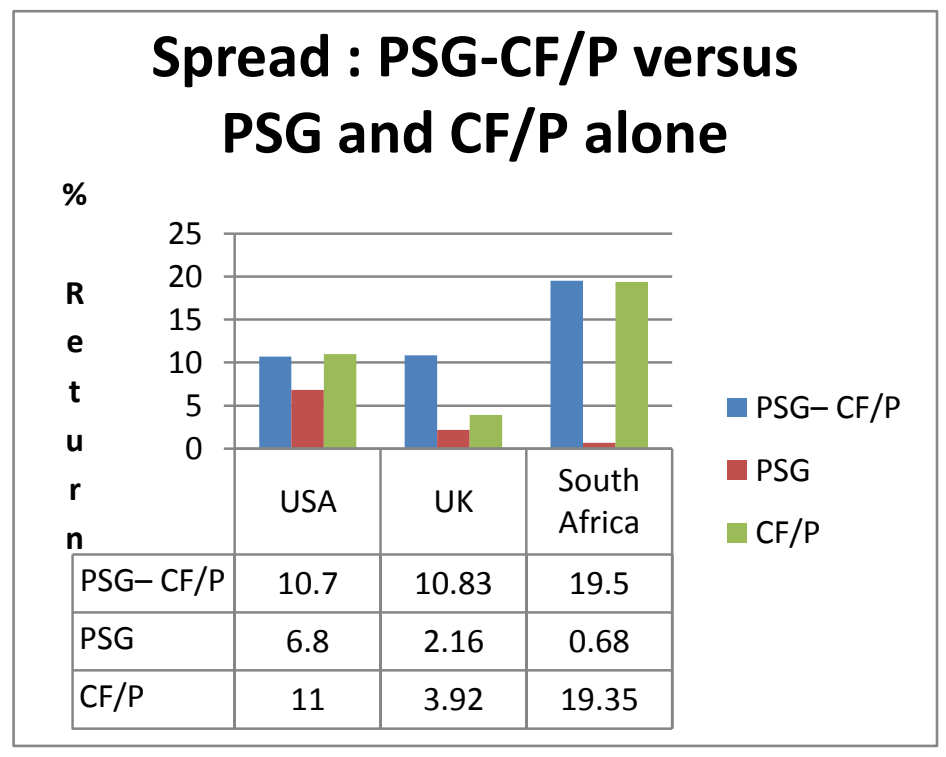

Figure 2 
The yield generated by the top value portfolio under the second two-dimensional test PSG-CF/P in the USA is $22.1 \%$, which is more than when portfolios are based on CF/P (20.1\%) or PSG (19.5\%) alone (the onedimensional ways). In the UK, the yield generated by the top value portfolio under PSG-CF/P is also more (24.14\%) than the yield generated by the top value portfolio based on PSG alone (21.05\%) and about the same than when portfolios are based on CF/P alone (24.49\%). Again, results from both developed countries are in contrast with the South African results. The yield of the top PSG-CF/P portfolio is less $(22.2 \%)$ than either of the top portfolios when applying the one-dimensional CF/P approach (29.69\%) and about identical to the result obtained when using PSG (22.28\%).

\section{DISCUSSION OF RESULTS}

On the one-dimensional tests, the spread (i.e. the difference in share price return between the top value portfolio and the top growth portfolio) is larger in South Africa than in developed countries, regardless of which measure of portfolio formation is used, with the single exception of CF/P. For CF/P, the spread on the European study is $20.8 \%$, which is slightly higher than the $19.35 \%$ on the South African study. The spread can be considered the size of the value premium, and it is clear the value premium is almost always larger in South Africa than in the developed world when one-dimensional tests are used. In addition, all South Africa's top value portfolios, whether based on BV/MV, CF/P, E/P, or PSG, generated a higher return than their international counterparts.

Results for the two-dimensional tests are less conclusive. On the second two-dimensional tests (PSG$\mathrm{CF} / \mathrm{P})$, South Africa also produced a higher spread (19.5\%) than any of the other countries in this study $(10.70 \%$ in the USA and $10.83 \%$ in the UK). However, the return generated by the top value portfolio in South Africa is identical to the USA ( $22 \%$ for both countries), but lower than the $24 \%$ generated by the top value portfolio in the UK. On the first two-dimensional test (PSG - BV/MV), the UK produced a higher spread $(11.81 \%)$ than South Africa $(9.5 \%)$. Additionally, the top value portfolio in both the USA and the UK produced higher returns than the top value portfolio in South Africa (21.12\% return in the USA, 25\% return in the UK, and only $18.9 \%$ in South Africa).

A surprising observation was provided by the UK results. On both one-and two-dimensional tests, the UK results stand out. The one-dimensional tests showed that the most profitable basis for portfolio formation in the UK is $\mathrm{BV} / \mathrm{MV}$, and not $\mathrm{CF} / \mathrm{P}$, as was the case for the other countries. On the basis of two-dimensional tests, the UK results were the only ones showing that PSG-CF/P produced a higher spread than CF/P ratios did on their own when used for portfolio formation. The UK observation may merit further study, considering that many multi-faceted and market-specific factors may be at play. One possible explanation may be that value-weighted portfolios were used in the UK study, while equally-weighted portfolios were used in all the other studies.

What was observed is that it is more profitable to base portfolio formation on two- as opposed to onedimensional criteria in the UK and the USA because either the spread between the value and growth portfolio in the two-dimensional case exceeds the spread in the one-dimensional case, or the returns generated by the top value portfolio under two-dimensional portfolio formation were higher than returns generated by the same portfolio under one-dimensional tests. However, the two-dimensional tests did not prove to be more profitable in the South African context. The top value portfolio under either of the two-dimensional tests in South Africa produced a lower return than the top value portfolio under the one-dimensional tests.

\section{CONCLUSION}

It can be concluded that the value premium is not just a first world phenomenon, but has also clearly been demonstrated in the financial market of a developing country such as South Africa. Results further show that, based on one-dimensional tests, the value premium in South Africa is higher than in any of the first world regions used for comparison in this study, except when $\mathrm{CF} / \mathrm{P}$ is used for portfolio formation. This higher value premium may be an indication of what was called a "Third World" premium, which reflects the greater risk exposure with which investors in smaller, less liquid markets have to contend (Rouwenhorst, 1999). 
However, when using two-dimensional tests, the results were less conclusive. In particular, the value premium is not more pronounced in South Africa when the first two-dimensional test (PSG - BV/MV) is used; and furthermore, under the second two-dimensional test (PSG-CF/P), the top value portfolio in South Africa does not outperform international counterparts, even if the spread is higher. The explanation for this finding may be what Schatzberg and Reiber (1992) identified as characteristics of less developed markets; namely, that they are dominated by small investors who do not instantaneously respond to new information.

\section{AUTHOR INFORMATION}

Anna Beukes (ABD) is an instructor at The Northern Alberta Institute of Technology (NAIT) in Edmonton, Alberta, Canada, where she teaches Finance and Economics. Prior to teaching, Anna worked as a Financial Analyst for an Investment Bank in Canada. She recently submitted her PhD dissertation and some of the results of that research are presented in this paper; which was also presented at the 2010 International Business \& Economics Research Conference.

\section{REFERENCES}

1. Antoniou A, Ergul N and Holmes P (1997). Market efficiency, thin trading and non-linear behaviour: Evidence from an emerging market. European Financial Management, 3: 175-190.

2. Auret CJ and Sinclaire R (2006). Book-to-market ratio and returns on the JSE. Investment Analysts Journal, 63: 31-38.

3. Bailey $G$ and Gilbert $E$ (2007). The impact of liquidity on mean reversion of shares returns of the JSE. Investment Analysts Journal, 66: 19-29.

4. Beukes A (2010). The existence of the value premium on the Johannesburg Stock Exchange from 1972 to 2001 and extrapolation as explanation. Ph.D. Thesis (unpublished), Grahamstown: Rhodes University

5. Brouwer I, Van Der Put J and Veld C (1997). Contrarian investment strategies in a European context. Journal of Business Finance \& Accounting, 24 (9/10): 1353-1366.

6. Chan LKC, Hamao Y and Lakonishok J (1991). Fundamentals and stock return in Japan. Journal of Finance, 46: 1739-1764.

7. Chopra N, Lakonishok J and Ritter J (1992). Measuring abnormal performance: Do stocks overreact? Journal of Financial Economics, 31: 235-268.

8. De Bondt WFM and Thaler R (1985). Does the stock market overreact? Journal of Finance, 40(3): 793805 .

9. Fama EF and French KR (1992). The cross-section of expected stock returns. Journal of Finance, 47: 427-486.

10. $\quad$---- (1998a). Value versus growth: The international evidence. Journal of Finance, 53: 1975-1999.

11. Fraser E and Page M (2000). Value and momentum strategies: Evidence from the Johannesburg Stock Exchange. Investment Analysts Journal, 51: 25-35.

12. Gates SR (1997). The market-to-book effect on the Johannesburg Stock Exchange. MBA Dissertation (unpublished), Johannesburg: University of the Witwatersrand.

13. Graham B and Dodd D (1934). Security Analysis. New York: McGraw-Hill.

14. Gregory A, Harris RDF and Michou M (2001). An analysis of contrarian investment strategies in the UK. Journal of Business Finance \& Accounting, 28(9-10):

15. 1193-1228.

16. Lakonishok J, Shleifer A and Vishny RW (1994). Contrarian investment, extrapolation, and risk. Journal of Finance, 49: 1541-1578.

17. Lo AW and MacKinlay AC (1990). Data-snooping biases in tests of financial asset pricing models. Review of Financial Studies, 3(3): 431-467.

18. Maritz AC and Klerck AC (1997). A test of Ben Graham's stock selection criteria on industrial stock traded on the JSE. Investment Analysts Journal, 45: 25-33.

19. Naughton $T$ and Veeraraghavan M (2005). A Multifactor model explanation of the anomalies in the cross-section of expected stock returns: Evidence from Indonesia, Singapore and Taiwan, Finance India, 19 (1): 135-157. 
20. Page MJ and Palmer F (1991). The relationship between excess returns, firm size and earnings on the Johannesburg Stock Exchange. South African Journal of Business Management, 22(3): 63-73.

21. Plaistowe T and Knight RF (1986). Premium to book value may be a contrary indicator. Investment Analysts Journal, 28: 35-39.

22. Robins EM, Sandler M and Durand F (1999). Inter-relationships between the January effect, market capitalisation and value investment strategies on the JSE. Investment Analysts Journal, 50(4): 53-64.

23. Rouwenhorst GK (1999). Local return factors and turnover in emerging stock markets. Journal of Finance, 54(4): 1439-1464.

24. Rosenberg B, Reid K and Lanstein R (1985). Persuasive evidence of market inefficiency. Journal of Portfolio Management, 11: 9-17.

25. Schatzberg JD and Reiber RP (1992). Extreme negative information and the market adjustment process: The case of corporate bankruptcy. Quarterly Journal of Business and Economics, 31: 3-21.

26. Van Rensburg P and Robertson M (2003a). Style characteristics and the cross-section of JSE returns. Investment Analysts Journal, 57: 1-10.

27. -------- (2003b). Size, price-to-earnings and beta on the JSE securities exchange. Investment Analysts Journal, 58: 7-16. 
NOTES 